\title{
DESIGN OF AN INDEGENISED NEGATIVE RESISTANCE CHARACTERISTICS CURVE TRACER
}

\author{
UMESH KUMAR* \\ Deptt. of Electrical Engineering, IIT, New Delhi-110016, India
}

(Received 18 February 2000; In final form 25 April 2000)

\begin{abstract}
"Negative Resistance" exhibited by a device during some portion of its V-I characteristics produces jump phenomenon, hysteresis and oscillation in the tracing circuitry. A method is presented to overcome the above problems in tracing the negative resistance characteristics of 2-terminal and 3-terminal devices by an indeginised curve plotter.
\end{abstract}

Keywords: Curve tracer; Negative resistance; V-I characteristics plotter; Negative resistance phenomenon; Tracing circuitry

\section{INTRODUCTION}

The invention of first negative resistance device dates back to 1918 with the invention of Dynatron by A. W. Hull. Many vacuum tube devices exhibiting a negative differential resistance have been invented since then and used in numerous applications. It was not until 1958 that the first negative resistance solid state device, called the Tunnel Diode was invented by Esaki. It took another eight years before another promising 2-terminal solid state negative resistance device, called the Gunn Diode, was invented.

As the name "Negative Resistance" seems to suggest that the device obeys Ohm's Law $(V=i R)$ with $R<0$, the invention created a flutter because it seems to violate the conservation of energy principle. This

*e-mail: umesh@ee.iitd.ernet.in 
controversy was quickly resolved when it became clear that device is actually non linear and that the term "Negative Resistance" implies only that the slope is negative at a certain region of the V-I characteristic. Without an external power source, a non-linear resistor can only absorb power; namely $P_{R}(t) \geq 0$. Such a resistor is said to be passive. Consequently, for any device without any internal biasing power supply, any point on the V-I curve having a negative slope must necessarily lie in the first and third quadrants only.

A common characteristic of a negative resistance device is that either the voltage is a multi-valued function of current (more than one voltage corresponds to some given value of current) or the current is a multivalued function of voltage (more than one current corresponds to some given value of voltage). In the first case, current is a single valued function of the voltage (but not vice versa); that is,

$$
i=\hat{i}(V)
$$

and is therefore called a voltage controlled resistor. In the second case, it is the voltage which is a single-valued function of current; that is,

$$
V=\hat{V}(i)
$$

And is therefore called a current controlled resistor. These are called Type-' $N$ ' devices and Type-' $S$ ' devices respectively (Fig. 1a).

A three terminal negative resistance device is one whose family of characteristics has at least one curve in the $V_{1}-i_{1}$ plane or $V_{2}-i_{2}$ plane exhibiting a negative slope region. A hypothetical example of a family of 3-terminal negative resistance device characteristics is shown in Figure $1 \mathrm{~b}$ both for Type- $N$ and Type- $S$ devices.
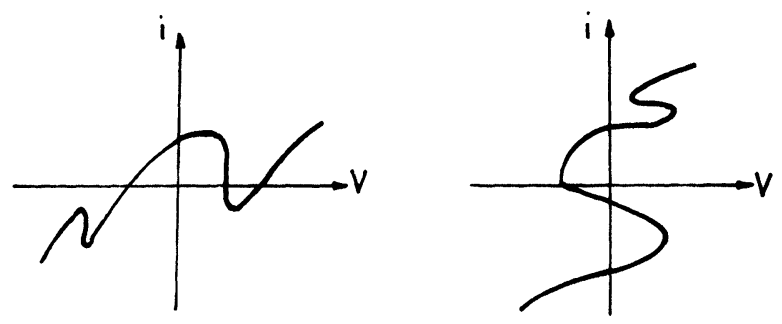

FIGURE 1a 

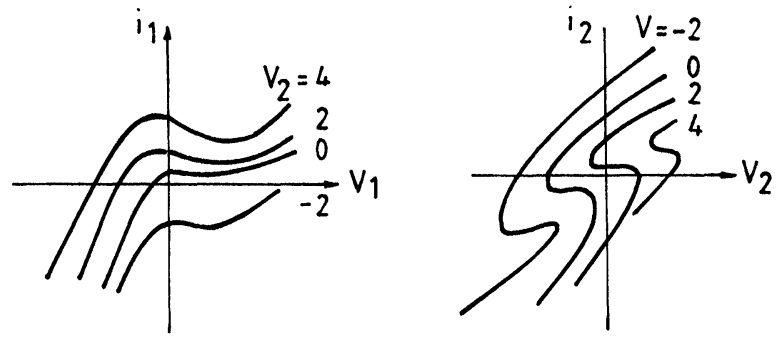

FIGURE 1b

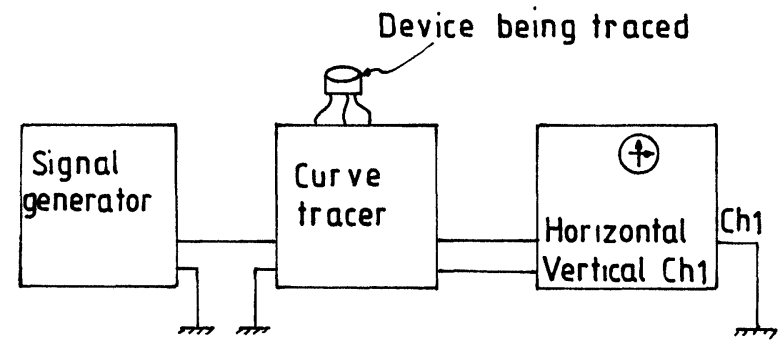

FIGURE 1c

This type of classification into Type- $N$ and Type- $S$ negative resistance devices is quite essential because the basic circuit adopted for curve tracing purpose differs for the two types.

In spite of the existence of a wide variety of negative resistance devices, very few tracings of such characteristics are available. The reason is that negative resistance curve can not be traced with commercially available curve tracers because "negative resistance" often causes jump phenomenon, hysteresis is and perennial oscillations in the tracing circuitry. Provision for overcoming all these problems are made in the curve tracer which we have indegenously fabricated with totally indegenised components (Fig. 1c).

The curve tracer is designed to trace either voltage controlled or current controlled negative resistance characteristics of both 2terminal and 3-terminal devices. All the six representations, which completely characterize a 3-terminal or 2-port non-linear resistor can be traced. It consists basically of three parts such as tracing signal generator; staircase signal generator and horizontal and vertical channel measurement circuits. 
The tracer signal generator circuit transforms the input signal into a voltage source or current source having several optional waveforms. Staircase signal generator circuit generates voltage or current increment signals so that family of characteristics describing a 3terminal or 2-port device can be traced in a single measurement setup. Vertical and horizontal channel measurement circuit measures the current and the voltage associated with the device under test. Detailed description of these circuits along with their figures now follows.

\section{DETAILED DESCRIPTION OF THE PRACTICAL CIRCUITS}

The Block Diagram of the built curve tracer is shown in Figure 2. There is a switch which is used to switch the tracing signal and staircase signal to different terminals of the device being traced. Inductor $L s$ is used to adjust the inductance in series with the current controlled 2-terminal device. Potentiometer $R p$ is used to adjust the shunt resistance. Potentiometer $R s$ and capacitance $C p$ are used to adjust the resistance in series and capacitance in parallel with the voltage controlled 2-terminal device being traced, respectively.

The input signals for driving the tracer signal generator are supplied by an external signal generator which can be any periodic waveform generator. But generally the waveform chosen is a sinusoidal signal. The output signals of the vertical and horizontal channel measurement circuits are applied to the vertical and horizontal terminals of the oscilloscope, respectively.

The three circuits namely, the tracing signal generator, the staircase signal generator and the vertical and horizontal channel measurement circuits are shown in Figures 3-5, respectively.

Switch SW2 switches different tracer and staircase signals to the associated terminals of 3-terminal device so that families of characteristics associated with anyone of the 6 representations of the device may be traced in a single set up position $1,2,3$ or 4 corresponds to switching the voltage-controlled, current-controlled, hybrid-2 or hybrid-1 representation of the device. Position 5 and 6 corresponds to switching the transmission-1 or transmission-2 representation of the device. 


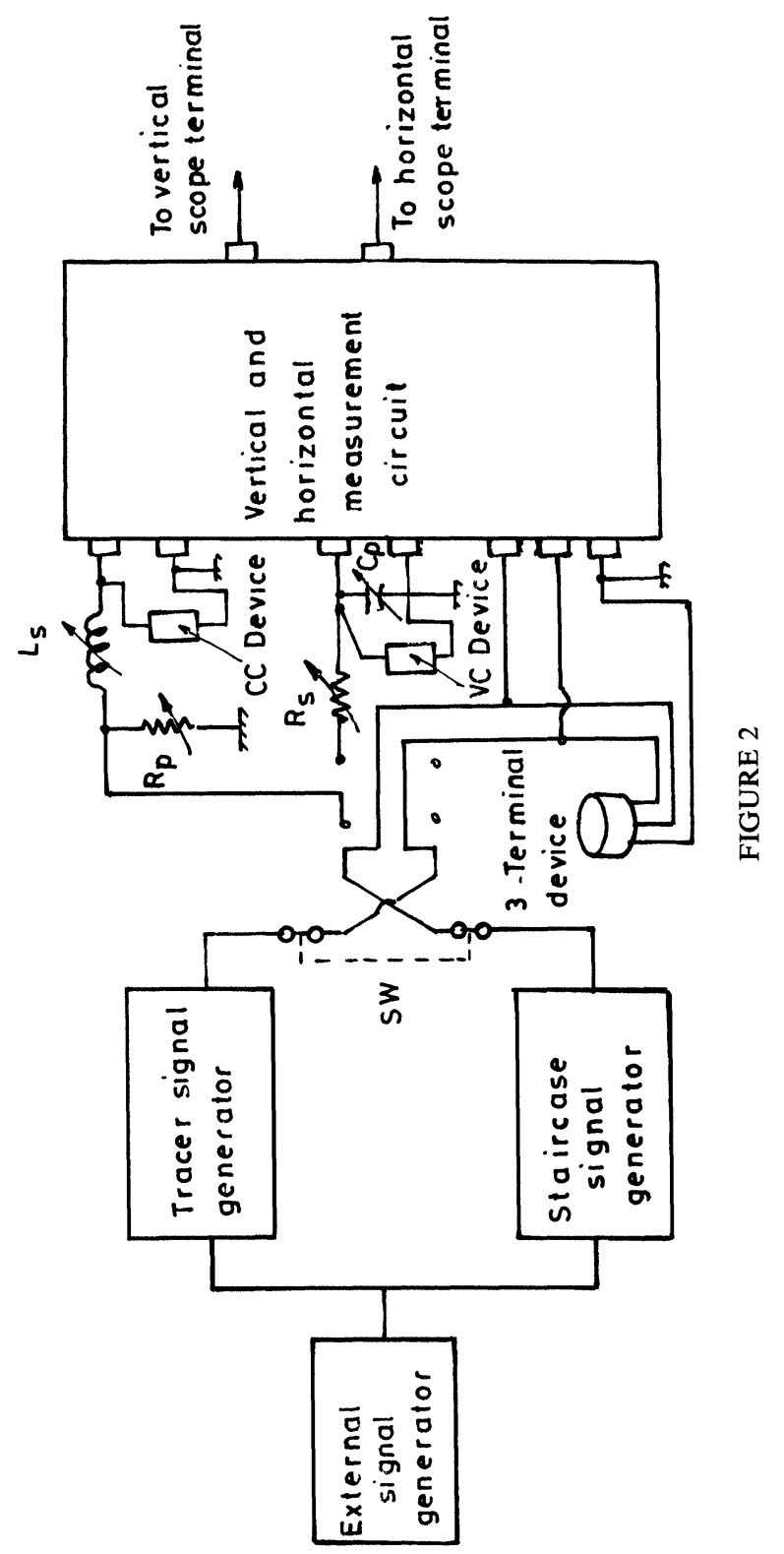




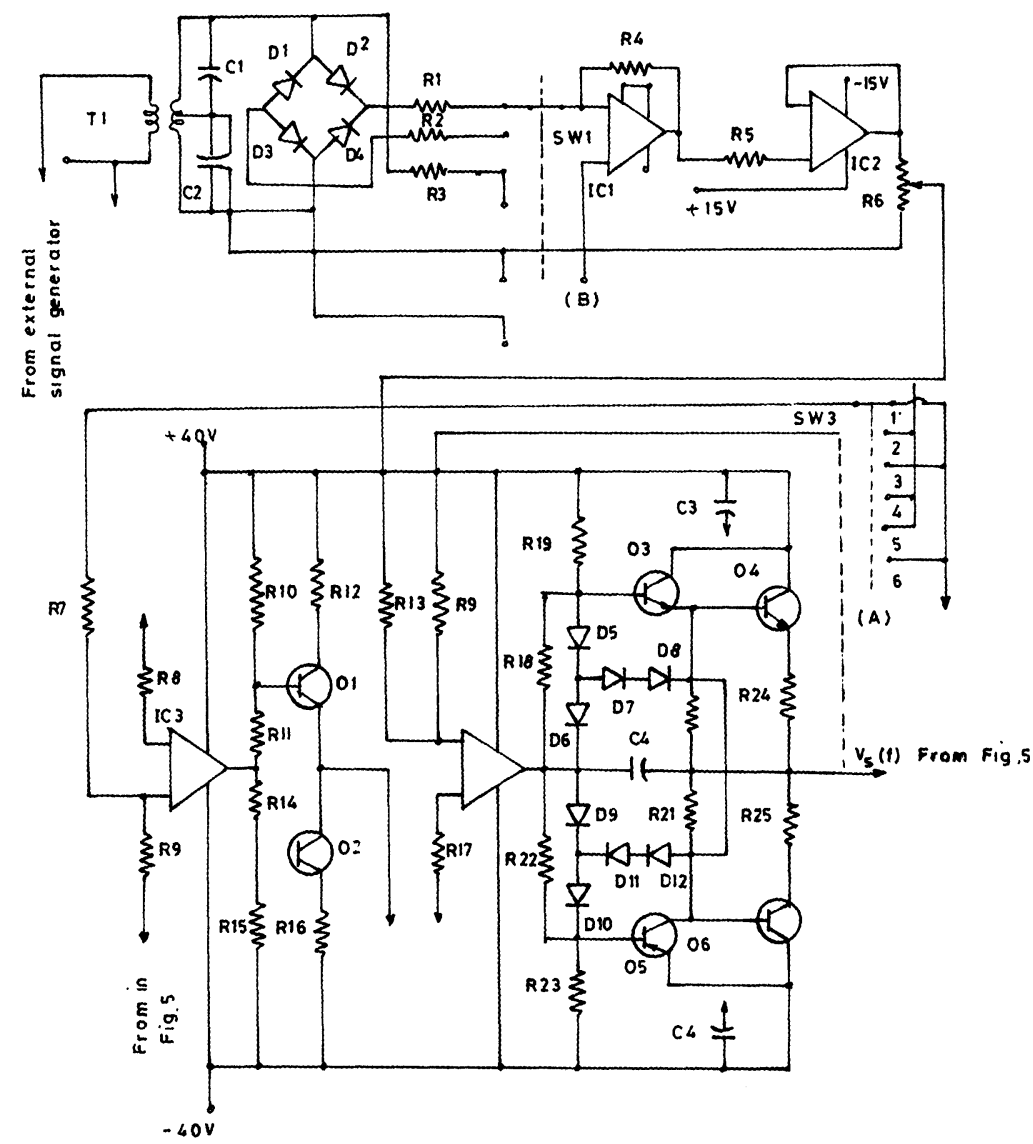

FIGURE 3

When tracing a 2-terminal voltage-controlled (Type- $N$ ) device, SW2 should be put to position 1, and when tracing a 2-terminal current-controlled (Type-S) device, SW2 should be put to position 2.

The position of switches SW 11 and SW 12 depend on whether the voltage or the current is measured. To measure the voltage across associated terminals of the device, put SW 11 and SW 12 to position $\mathrm{V}$, and to measure the current through the associated terminals of the device, set SW 12 and SW 12 to position I, respectively. 


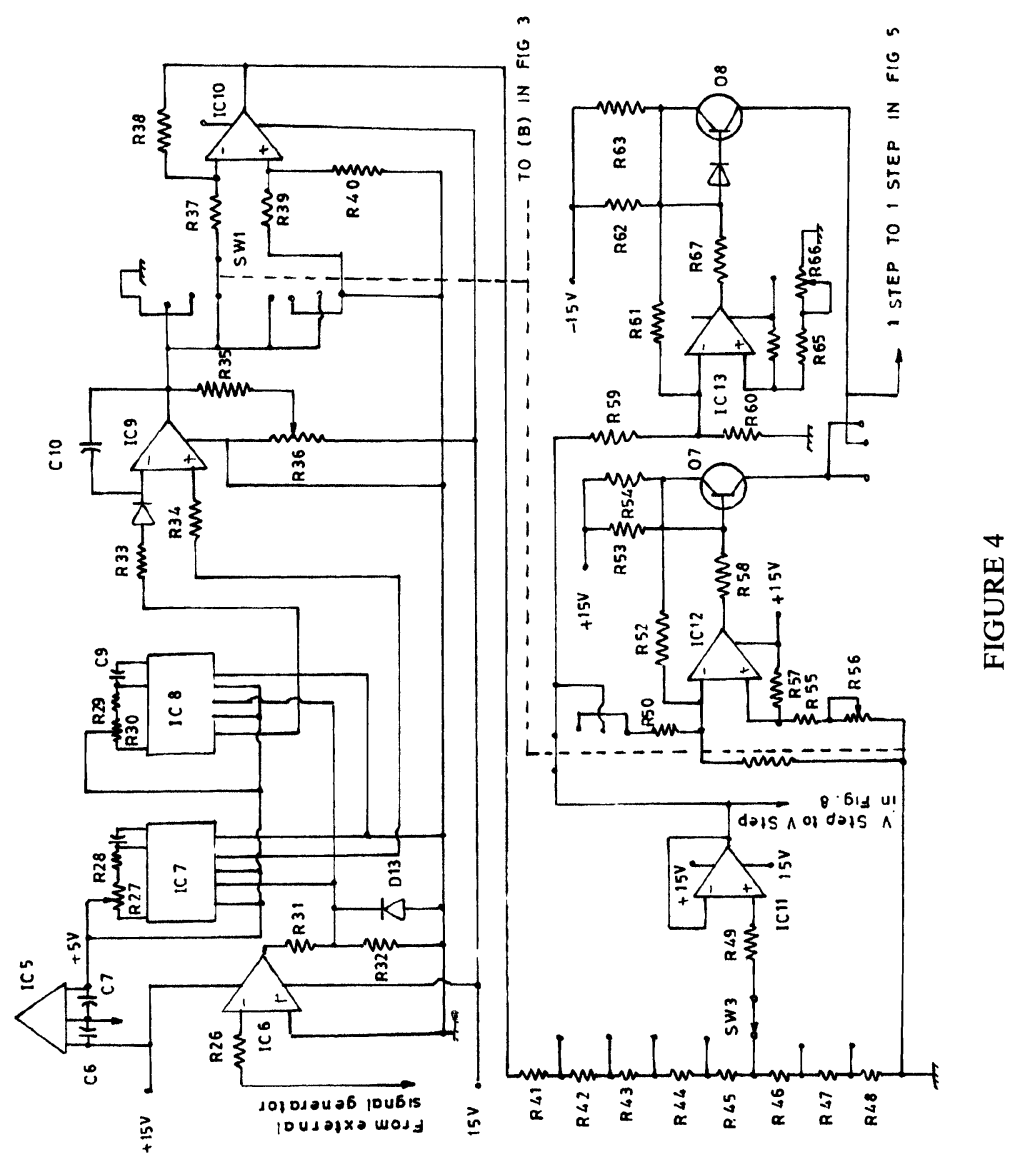




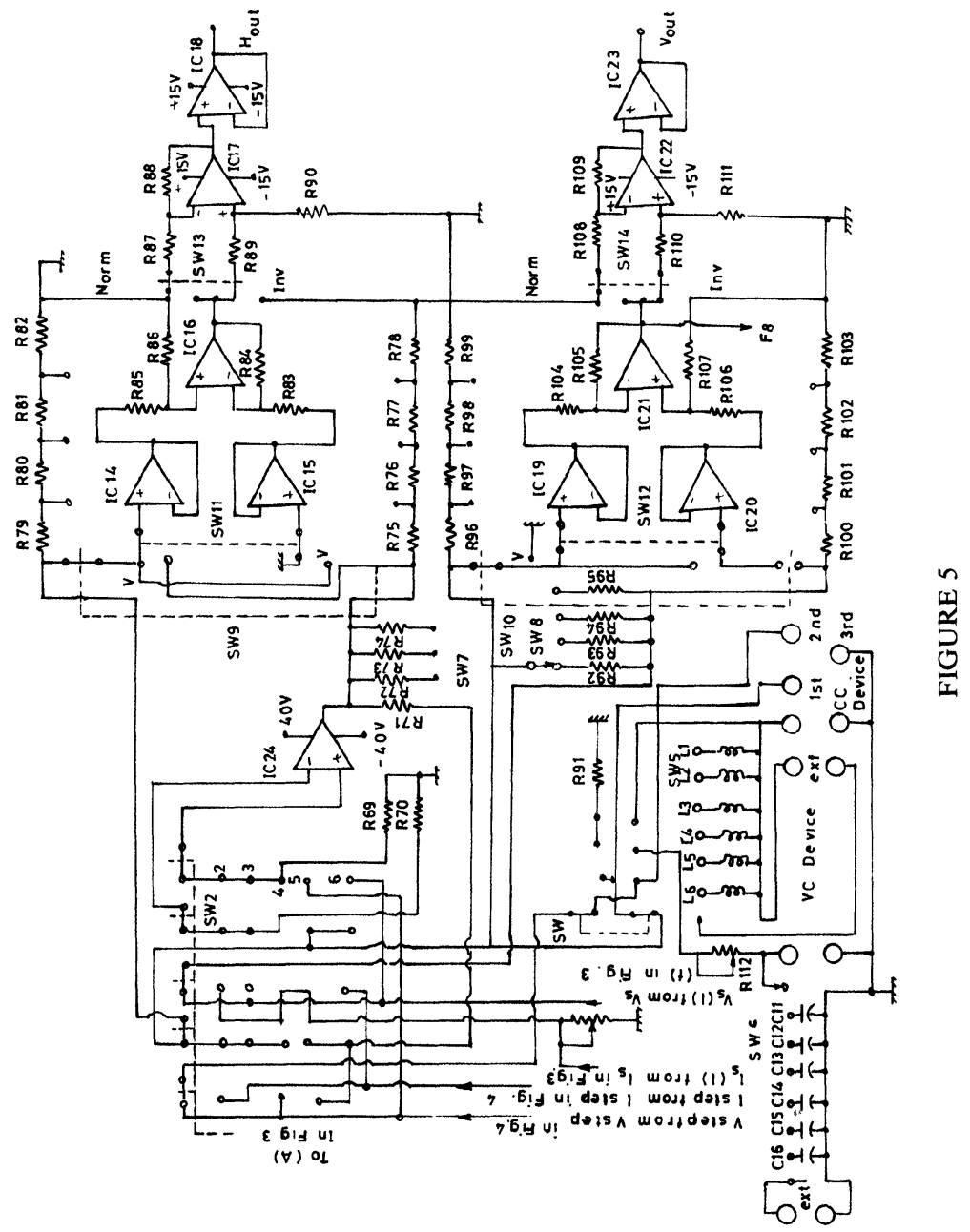




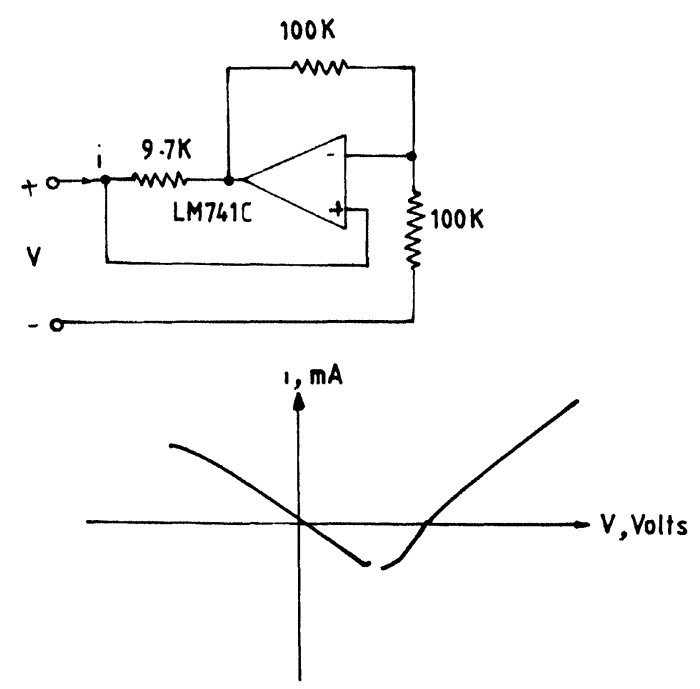

FIGURE 6 Voltage-controlled 2-terminal (1-port) device.

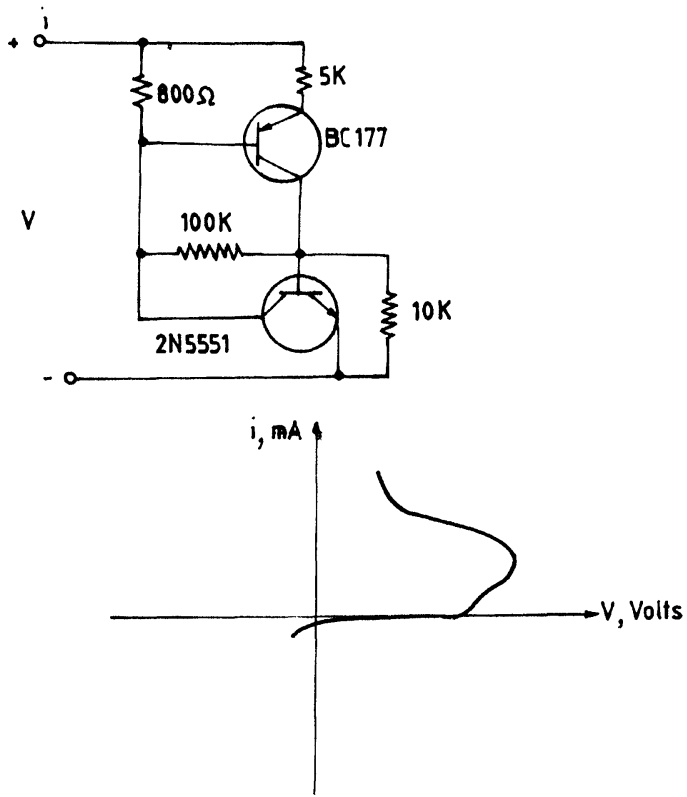

FIGURE 7 Current-controlled 1-port device. 
TABLE I The catalog of components

\begin{tabular}{|c|c|c|c|}
\hline Part no. & Description & Part no. & Description \\
\hline $\mathrm{R}_{1}$ & $10 \mathrm{k}$ & $\mathbf{R}_{99}, \mathbf{R}_{103}$ & \\
\hline $\mathbf{R}_{2}$ & $10 \mathrm{k}$ & $\mathbf{R}_{83}, \mathbf{R}_{84}$ & $30 \mathrm{k}$ \\
\hline $\mathbf{R}_{3}$ & $62 \mathrm{k}$ & $\mathbf{R}_{85}$ & $30 \mathrm{k}$ \\
\hline $\mathrm{R}_{4}$ & $330 \mathrm{k}$ & $\mathbf{R}_{86}$ & $30 \mathrm{k}$ \\
\hline $\mathrm{R}_{5}$ & $20 \mathrm{k}$ & $\mathbf{R}_{87}, \mathbf{R}_{88}$ & $30 \mathrm{k}$ \\
\hline $\mathbf{R}_{6}$ & $10 \mathrm{k}_{(\mathrm{VR})}$ & $\mathbf{R}_{89}, \mathbf{R}_{90}$ & $30 \mathrm{k}$ \\
\hline $\mathrm{R}_{7}$ & $10 \mathrm{k}$ & $\mathrm{R}_{112}$ & $1 \mathrm{k}_{(\mathrm{VR})}$ \\
\hline $\mathbf{R}_{8}$ & $10 \mathrm{k}$ & $\mathbf{R}_{91}$ & $1 \mathrm{k}$ \\
\hline $\mathbf{R}_{\mathbf{9}}, \mathbf{R}_{\mathbf{g}^{\prime}}$ & $100 \mathrm{k}$ & $\mathbf{R}_{92}$ & $1 \mathrm{k}$ \\
\hline $\mathbf{R}_{10}$ & $3.9 \mathrm{k}$ & $\mathrm{R}_{93}$ & $500 \Omega$ \\
\hline $\mathrm{R}_{11}$ & $22 \mathrm{k}$ & $\mathbf{R}_{94}$ & $100 \Omega$ \\
\hline $\mathbf{R}_{12}$ & $680 \Omega$ & $\mathrm{R}_{95}$ & $10 \Omega$ \\
\hline $\mathrm{R}_{13}$ & $10 \mathrm{k}$ & $\mathbf{R}_{104}$ & $30 \mathrm{k}$ \\
\hline $\mathrm{R}_{14}$ & $22 \mathrm{k}$ & $\mathrm{R}_{105}$ & $30 \mathrm{k}$ \\
\hline $\mathbf{R}_{15}$ & $3.9 \mathrm{k}$ & $\mathbf{R}_{106}$ & $30 \mathrm{k}$ \\
\hline $\mathbf{R}_{16}$ & $680 \Omega$ & $\mathbf{R}_{107}$ & $30 \mathrm{k}$ \\
\hline $\mathbf{R}_{17}$ & $10 \mathrm{k}$ & $\mathbf{R}_{108}$ & $30 \mathrm{k}$ \\
\hline $\mathbf{R}_{18}$ & $2.2 \mathrm{k}$ & $\mathbf{R}_{109}$ & $30 \mathrm{k}$ \\
\hline $\mathbf{R}_{19}$ & $22 \mathrm{k}$ & $\mathbf{R}_{110}$ & $30 \mathrm{k}$ \\
\hline $\mathbf{R}_{20}$ & $100 \Omega$ & $\mathbf{R}_{111}$ & $30 \mathrm{k}$ \\
\hline $\mathbf{R}_{21}$ & $100 \Omega$ & $\mathrm{C}_{1}$ & $0.1 \mu \mathrm{F}$ \\
\hline $\mathbf{R}_{22}$ & $2.2 \mathrm{k}$ & $\mathrm{C}_{2}$ & $0.1 \mu \mathrm{F}$ \\
\hline $\mathrm{R}_{23}$ & $22 \mathrm{k}$ & $\mathrm{C}_{3}$ & $0.1 \mu \mathrm{F}$ \\
\hline $\mathbf{R}_{24}$ & $10 \Omega$ & $\mathrm{C}_{4}$ & $0.10 \mu \mathrm{F}$ \\
\hline $\mathbf{R}_{25}$ & $10 \Omega$ & $\mathrm{C}_{5}$ & $0.01 \mu \mathrm{F}$ \\
\hline $\mathbf{R}_{26}$ & $20 \mathrm{k}$ & $\mathrm{C}_{6}$ & $0.2 \mu \mathrm{F}$ \\
\hline $\mathbf{R}_{27(\mathrm{VR})}$ & $10 \mathrm{k}$ & $\mathrm{C}_{7}$ & $0.1 \mu \mathrm{F}$ \\
\hline $\mathbf{R}_{28}$ & $100 \Omega$ & $\mathrm{C}_{8}$ & $0.01 \mu \mathrm{F}$ \\
\hline$R_{29(V R)}$ & $50 \mathrm{k}$ & $\mathrm{C}_{9}$ & $10 \mu \mathrm{F}$ \\
\hline $\mathbf{R}_{30}$ & $1 \mathrm{k}$ & $\mathrm{C}_{10}$ & $0.01 \mu \mathrm{F}$ \\
\hline $\mathbf{R}_{31}$ & $10 \mathrm{k}$ & $\mathrm{C}_{11}$ & $-0.01 \mu F$ \\
\hline $\mathbf{R}_{32}$ & $5.6 \mathrm{k}$ & $\mathrm{C}_{12}$ & $0.05 \mu \mathrm{F}$ \\
\hline $\mathbf{R}_{33}$ & $3 \mathrm{k}$ & $\mathrm{C}_{13}$ & $0.1 \mu \mathrm{F}$ \\
\hline $\mathbf{R}_{34}$ & $30 \mathrm{k}$ & $\mathrm{C}_{14}$ & $0.56 \mu \mathrm{F}$ \\
\hline $\mathbf{R}_{35}$ & $2.2 \mathrm{k}_{(\mathrm{VR})}$ & $\mathrm{C}_{15}$ & $1 \mu \mathrm{F}$ \\
\hline $\mathbf{R}_{36}$ & $10 \mathrm{k}_{(\mathrm{VR})}$ & $\mathrm{C}_{16}$ & $2.2 \mu \mathrm{F}$ \\
\hline $\mathbf{R}_{37}$ & $100 \mathrm{k}$ & & \\
\hline $\mathbf{R}_{38}$ & $100 \mathrm{k}$ & & \\
\hline $\mathbf{R}_{39}$ & $100 \mathrm{k}$ & & \\
\hline $\mathbf{R}_{\mathbf{4 0}}$ & $100 \mathrm{k}$ & & \\
\hline $\mathbf{R}_{41}$ & $500 \mathrm{k}$ & & \\
\hline$R_{42}$ & $300 \mathrm{k}$ & & \\
\hline $\mathbf{R}_{\mathbf{4 3}}$ & $100 \mathrm{k}$ & $\mathrm{T}_{1}$ & $1: 1$ transformer \\
\hline $\mathbf{R}_{44}$ & $50 \mathrm{k}$ & $D_{1}-D_{4}$ & $1 N 4448$ \\
\hline $\mathbf{R}_{45}$ & $30 \mathrm{k}$ & $D_{5}-D_{12}$ & $1 \mathrm{~N} 4003$ \\
\hline $\mathrm{R}_{65}$ & $91 \mathrm{k}$ & $\mathrm{IC}_{9}$ & 1/4 LM322 \\
\hline $\mathrm{R}_{66}$ & $10 \mathrm{k}_{\mathrm{VR}}$ & $\mathrm{IC}_{10}$ & LM 741C \\
\hline $\mathbf{R}_{67}$ & $20 \mathrm{k}$ & $\mathrm{IC}_{11}$ & LM 741C \\
\hline $\mathbf{R}_{68}$ & $1 \mathrm{M}_{(\mathrm{VR})}$ & $\mathrm{IC}_{12}$ & $1 / 4$ LM 324 \\
\hline $\mathbf{R}_{69}$ & $30 \mathrm{k}$ & $\mathrm{IC}_{13}$ & LM 741C \\
\hline $\mathbf{R}_{70}$ & $30 \mathrm{k}$ & $\mathrm{IC}_{14}$ & $1 / 4 \mathrm{TL} 084 \mathrm{CN}$ \\
\hline
\end{tabular}


TABLE I (Continued)

\begin{tabular}{lccr}
\hline Part no. & Description & Part no. & Description \\
\hline $\mathbf{R}_{71}$ & $1 \mathbf{k}$ & $\mathrm{IC}_{156}$ & $1 / 4 \mathrm{TL} 084 \mathrm{CN}$ \\
$\mathbf{R}_{72}$ & $500 \Omega$ & $\mathrm{IC}_{16}$ & $1 / 4 \mathrm{TL} 084 \mathrm{CN}$ \\
$\mathbf{R}_{73}$ & $100 \Omega$ & $\mathrm{IC}_{17}$ & $1 / 4 \mathrm{TL} 084 \mathrm{CN}$ \\
$\mathbf{R}_{74}$ & $10 \Omega$ & $\mathrm{IC}_{18}$ & $1 / 4 \mathrm{TL} 084 \mathrm{CN}$ \\
$\mathbf{R}_{75}, \mathbf{R}_{79}$ & $5 \mathrm{M}$ & $\mathrm{IC}_{19}$ & $1 / 4 \mathrm{TL} 084 \mathrm{CN}$ \\
$\mathbf{R}_{96}, \mathbf{R}_{100}$ & & $\mathrm{IC}_{20}$ & $1 / 4 \mathrm{TL} 084 \mathrm{CN}$ \\
$\mathbf{R}_{76}, \mathbf{R}_{80}$ & $3 \mathrm{M}$ & $\mathrm{IC}_{21}$ & $1 / 4 \mathrm{TL} 084 \mathrm{CN}$ \\
$\mathbf{R}_{97}, \mathbf{R}_{101}$ & & $\mathrm{IC}_{22}$ & $1 / 4 \mathrm{TL} 084 \mathrm{CN}$ \\
$\mathbf{R}_{77}, \mathbf{R}_{81}$ & $1 \mathrm{M}$ & $\mathrm{IC}_{23}$ & $1 / 4$ TL 084 CN \\
$\mathbf{R}_{98}, \mathbf{R}_{102}$ & & $\mathrm{IC}_{24}$ & LM 308 \\
$\mathbf{R}_{78}, \mathbf{R}_{82}$ & $1 \mathrm{M}$ & & \\
\hline
\end{tabular}

[VR = Variable Resistance].

\section{EXPERIMENTAL RESULTS}

Figures 6 and 7 show the negative resistance characteristics experimentally traced for a Type- $N$ and a Type- $S$ device respectively as an example.

\section{CONCLUSION}

We have tried to indigenise the negative resistance curve-tracer as for as possible. However, some of the components can not be procured in Indian markets, as we found after repeated searches. The curve tracer built has been successfully tested for as many devices as we could. Further work can be done to elaborate and extrapolate the present curve tracer to make it more accurate, closer and nearer to the original work of Leon Chua and his students in IEEE transactions on circuits and systems. The complete catalog of components is given in Table I.

\section{References}

[1] Chua, L. O. and Yu, J. B. (1983). "Negative Resistance Devices", Int. J. Circuit Theory and Applications, 11.

[2] Chua, L. O., Yu, J. B. and Yu, Y. Y. (1985). "Bipolar - JFET-MOSFET negative resistance devices", IEEE Transactions on Circuits and Systems, CAS-32.

[3] Chua, L. O., Introduction to Non-Linear Network Theory, New York: McGraw Hill, 1969. 

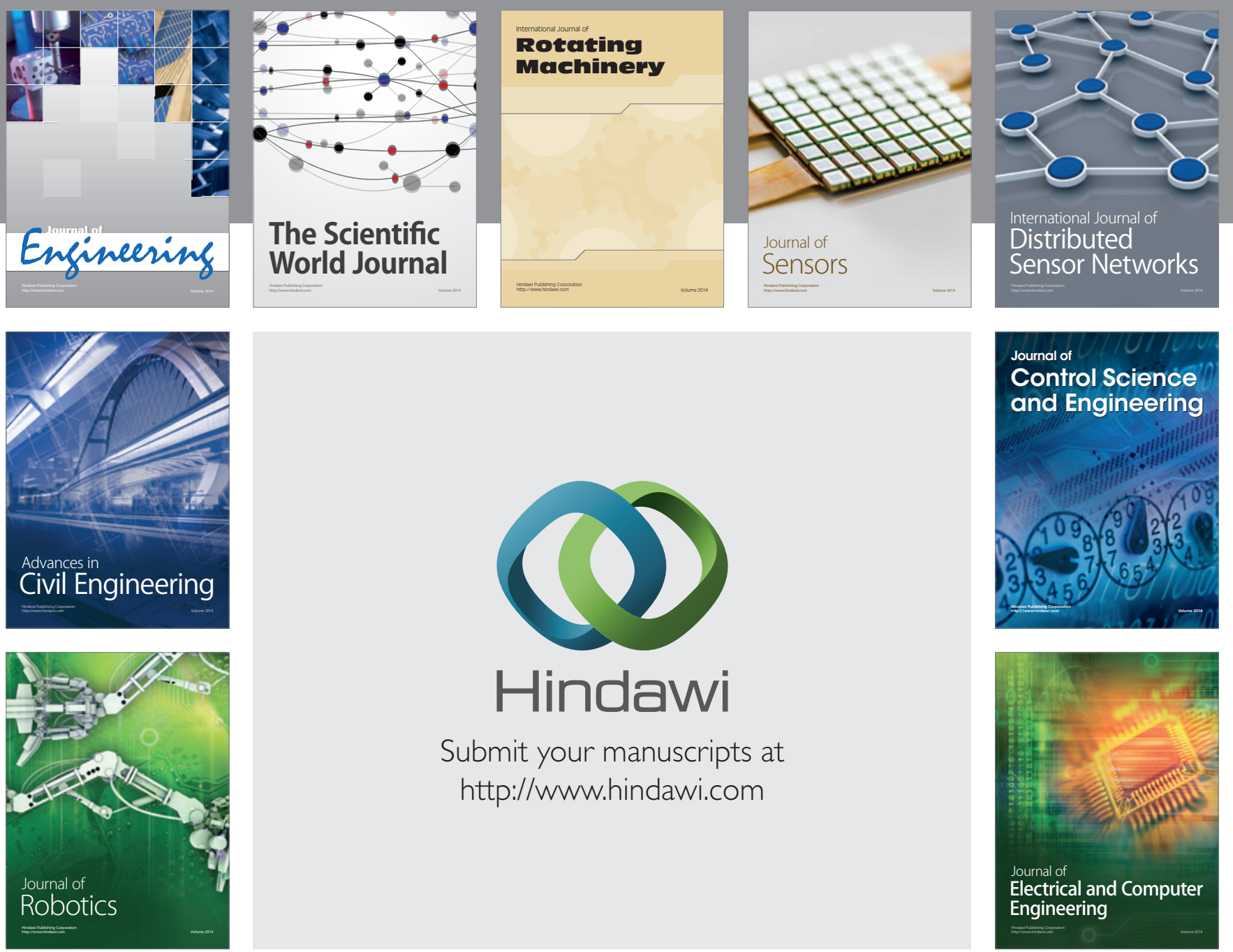

Submit your manuscripts at

http://www.hindawi.com
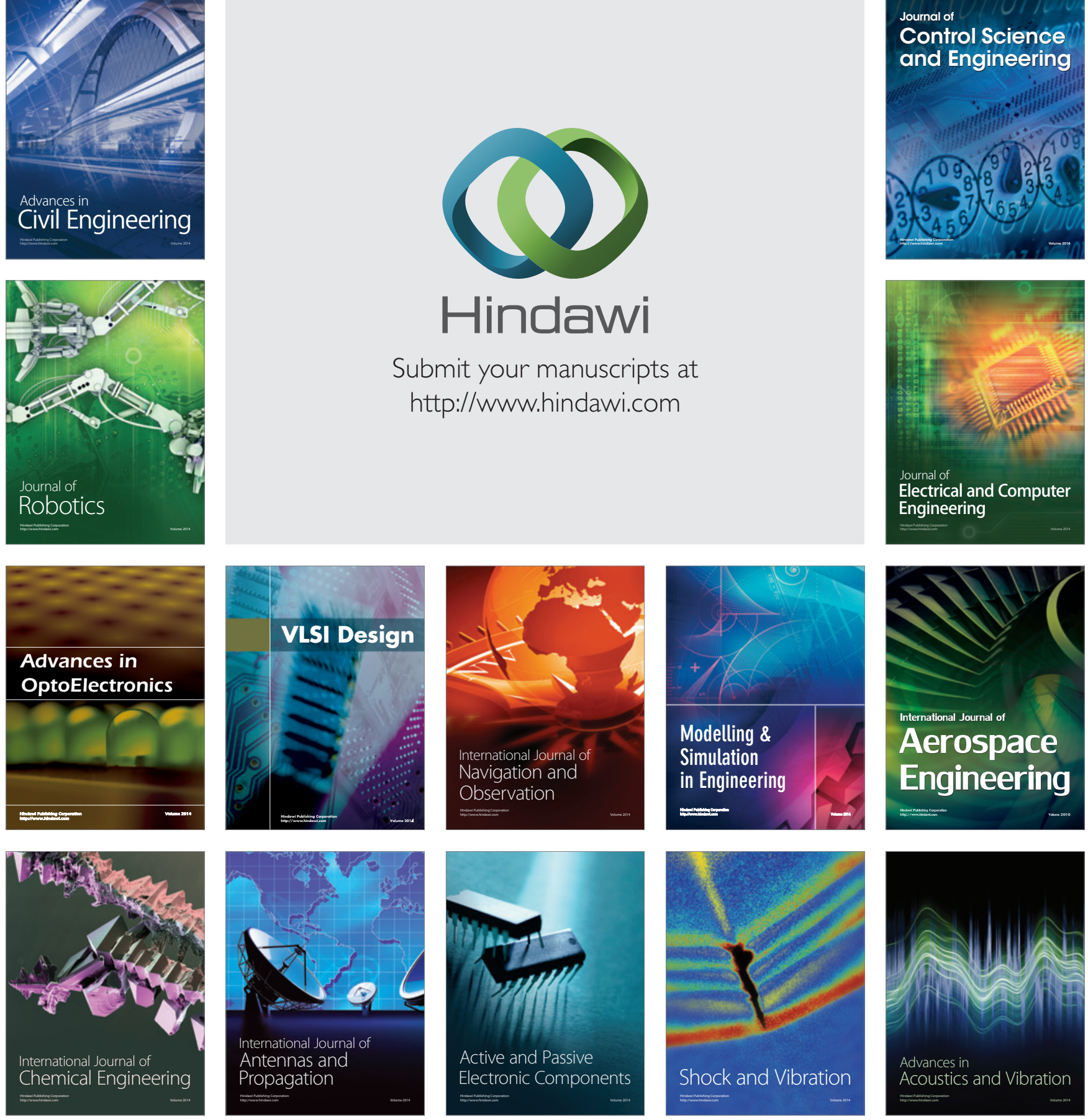